\title{
Incentive Contracts with Unobservable Competence Levels
}

\author{
Jerome Davis $^{1}$ and Hans Keiding ${ }^{*}, 2$
}

\author{
${ }^{1}$ Dalhousie University, Canada \\ ${ }^{2}$ University of Copenhagen, Denmark
}

\begin{abstract}
A contract where the agent is compensated ex post only upon satisfactory performance, often called a no-cureno-pay contract, can arise as under several circumstances. In this paper, we model the problem of contractual choice as a principal-agent contract which is modified due to hidden information about the competence of the agent to fulfill the obligations of the contract. The agent offers a choice of contracts to the principal, thereby signalling agent competence to the principal, and there is no alternative reputation mechanism to the contract for the principal's bargaining strategy. It turns out that in this situation, the optimal contract will have a form which may be recognized as a no-cure-no-pay contract.
\end{abstract}

Keywords: Contracts, no-cure-no-pay, principal-agent model, asymmetric information.

\section{INTRODUCTION}

In recent years, there has been an increasing interest in analyzing contract forms. The type of contract which arises in a particular economic context will usually be a reflection of the underlying economic conditions, and the contract forms prevailing in different kinds of business, such as banking, insurance, healthcare etc. display features which can be traced back to the basic economic relationship between the parties. But while the understanding of the nature of contracts is growing, the same contracts tend to change over time. Thus, various forms of contracts originating in maritime salvage and US tort practice have emerged in recent years. This is particularly the case for professional service firms where the use of "unconditional service guarantees" is becoming more and more widespread. These latter are seen as a form of signalling in intensely competitive markets, and hotel, health care, investment banking, and accounting firms attempt such contracting in order to win market share. In this paper we explore the formal conditions under which both principal and agent prefer to enter into such contracts.

Where unconditional service guarantees as offered by professional service firms represent a trend covering about twenty five years, maritime salvage contracting and US law firm contingent legal fee contracts have been in existence for a much longer time. No-cure-no-pay provisions in maritime salvage contracting datefrom the Rhodian maritime law in Hellenistic Greece. Similarly, no-win-no-fee contracting between client and lawyer in US tort law spread widely throughout the United States in the19th Century, so that it was sanctioned by the American Bar Association through the latter's adoption of canon 13 of the ABA Code of Ethics in 1908 [1]. In maritime salvage and contingent fee contracting, the agent is compensated ex post only upon satisfactory performance. The rate of agent compensation is a function of

*Address correspondence to this author at the Department of Economics, University of Copenhagen, Studiestraede 6, DK-1455, Copenhagen K, Denmark; Tel: +45 35323089; E-mail: hans.keiding@econ.ku.dk the property or service on which the agent has a lien, the value of ship, cargo or tort law suit, and of the risk borne by the agent.

There has been little theoretical focus on the underlying conditions by which both principal and agent in very diverse fields of business prefer to enter into contracts of the above type. With regard to maritime salvage contracting, this may be due to lack of economic analysis of such contracting generally [2, 3], for analyses of maritime salvage in the broader context of voluntary rescue). Literature on service guarantee contracts is similarly sparse. Coverage of the topic is either general without an analysis of the contractual incentive aspects [4], or is specifically directed to the introduction of such contracts into specific professional services [5]. In contrast there is a voluminous literature on contingent fee contracts. Analysed phenomena are numerous and the following is just a sampling of the more recent literature: contingent fees versus fixed fees or hourly fees for lawyer services [1, 6-9]; contingent fees and the trade-offs between out of court settlement versus going to trial $[10,11]$; the efficiency of the contingent fee system [12-14]; and, even the impact of contingent fee rents on the market for lawyers [15].

In this paper we introduce a formal model of contracting in order to see how specific contracts may emerge as preferred contract forms in situations where one party has restricted access to information about capability and effort of the other contracting party. The model is a version of the principal-agent model to which we have added another element of asymmetric information: the principal cannot observe the agent's capability to do the job at hand (even in the case of high agent effort). In the formal set-up to be studied, the agent offers the principal the contract under which he proposes to work, and the principal accepts or rejects the contract. This contract may thus be used as a signal of agent capability, and in the resulting game we study the perfect Bayesian equilibria that may occur. It turns out that on weak assumptions on beliefs, these contracts exhibit only equilibria which are separating in the sense that competent 
and incompetent agents propose different contracts. This property may then be used to exhibit the emergence of nocure-no-pay contracts in the limiting case of total agent incompetence.

The idea of explaining no-cure-no-pay by double information asymmetry is not new; notably, the work on no-cureno-pay contracts by Rubinfeld and Scotchmer [6] on contingent fee also uses the framework of the principal-agent model. However, in their model clients (principals) signal quality of their case whereas lawyers may choose different effort levels. In our setup, signalling is all on the part of the agent; this seems to fit better with at least some of the realworld instances of no-cure-no-pay contracts and in any case provides an alternative explanation which works in the case of lawyer fees when the cases are sufficiently transparent.

Finally, it should be mentioned that the case of no payment in case of failure does not pose a logical lower limit what can happen in incentive contracts, since one might also consider inverse payments, giving rise to what is known as super-contingent fee contracts $[16,17]$. Such contracts are however outside the scope of the present paper.

The paper is organized as follows: In Section 2, we introduce the formal model in a rather general setup and present a first result on the emergence of contracts with no-cure-nopay features as signals of competence, followed by a treatment of a simpler version of the model, where we describe the equilibria which may occur. In Section 3 we discuss the extent to which the results fits with the actual situation in the fields which gave rise to this study, and Section 4 contains some concluding remarks. Proofs of the propositions in the paper are given in Section 5.

\section{A PRINCIPAL-AGENT MODEL WITH HIDDEN INFORMATION ON AGENT CAPABILITY}

In this section, we present a simple model of the situation where a service is to be provided but where the recipient has no access to information about effort as well as the overall ability of the provider to carry out the task. The model is a version of the well-known principal-agent model [18-20], and only a few changes in the basic framework are needed: We add that the agents come with varying degree of competence, something which cannot be observed by the principal. Thus, in our model, hidden action and hidden information come together, actually a very widespread feature of realworld contractual relationships.

There are two individuals, denoted 'principal' and 'agent'. If the parties contract, the outcome to the principal takes the form of a money payoff $b$ with values in an interval $\left[b_{1}, b_{2}\right]$, which is subject to uncertainty. Th probability of outcome depends on the agent's type $t$ and her effort $e$, described by a probability distribution function $F(b \mid t, e)$ with density $f(b \mid t, e)$ (so that $f(b \mid t, e)=F^{\prime}(b \mid t, e)$ ). We assume that both type and effort take values between 0 and 1 ; increasing $t$ is interpreted as increasing competence, and similarly, higher value of $e$ means that more effort is put forward.
Only the final outcome $b$, but neither $t$ nor $e$ is observed by the principal. A contract between principal and agent specifies a payment to the agent, which can depend only on what is observable to both, that is the final outcome. Therefore, contracts are functions $r:\left[b_{1}, b_{2}\right] \rightarrow \mathbf{R}$, where $r(b)$ is the payment to the agent when outcome is $b$.

We assume that the agent is risk averse with utility $u(\rho, e)=V(\rho)-K(e)$,

where $V$ is a strictly concave function of the payment from the principal $\rho$, normalized so that $V(0)=0$, while $K$ is an increasing function of $e$, describing disutility of effort $e$. Since payment will depend on random outcome $b$, the contract $r$ will be evaluated by expected utility $U_{t}(r, e)=\int_{b_{1}}^{b_{2}}(V(b)-K(e)) f(b \mid t, e) d b$, which depends on $t$ through the probability density function $f$. There is a given reservation utility $U_{t}^{0} \geq 0$ for the agent of type $t$, reflecting what could be obtained by contracting elsewhere.

The principal is assumed to be risk neutral, so that what matters is expected net payoff, written as $\Pi(r, e)$. Here expectation must be taken both over outcome and over type of agent, which is assumed to be distributed in society in accordance with a probability distribution function $G(t)$ with density $g(t)$.

We put some restrictions on the set $\mathcal{R}$ of admissible contracts $r(b)$. Thus, (i) the payment is never negative and cannot exceed the gain of the principal, formally $0 \leq r(b) \leq b$ for all $b$, and (ii) if $b^{\prime}>b$, then $r\left(b^{\prime}\right) \geq r(b)$, higher outcome to the principal does not reduce payments to the agent. This seems realistic and may also be defended as an incentive compatibility condition in the case where the agent delivers the outcome to the principal, since reduction of payment for a higher outcome might lead to the throwing away of part of the outcome.

While the model constructed so far differs only slightly from the standard principal-agent model, we shall give it a somewhat unusual turn by emphasizing the role of the agent: Rather than having the principal choose a contract which the agent may take or leave, we reverse the roles so that the agent proposes a contract which may or may not be accepted by the principal. This is more in line with our interpretation, and it allows for a new aspect in the game under uncertainty considered, namely signalling; the agent sends a signal about her capabilities by proposing a contract to the principal. Intuitively, the agent signals capability by proposing a contract which would be disadvantageous for an incompetent agent.

The time schedule of our game is as follows: First of all, the agent (of given type) proposes a contract. Then the principal chooses whether to accept or reject. If the contract is rejected, the game ends, and the players get their reservation utilities; if it is accepted, the agent chooses an effort level. We shall be interested in contracts that are acceptable for the principal given the beliefs about agent competence obtained from inspecting the proposal, and on the other hand are such 
that if they are actually carried through, the agent will choose the effort level which maximizes expected utility (a choice which is assumed to be uniquely determined at equilibrium). Technically, we are considering perfect Bayesian equilibria of the game.

Formally, an equilibrium is a pair $\left(a,\left(r_{t}, e_{t}\right)_{t \in[0,1]}\right)$, where $a$ is a (decision) function taking one of two values ( 1 for "accept" and 0 for "reject") on each feasible contract $r \in$ $\mathcal{R}$, while $r_{t}$ is the contract proposed by the agent of type $t$, and $e_{t}$ is the effort chosen by this agent (given that the contract is accepted by the principal). The equilibrium properties are as follows: For the principal, the contract $r_{t}$ is accepted if ex post expected net gain is nonnegative, where expectation is taken with respect to the posterior probability distribution over types,

$$
\int_{b_{1}}^{b_{2}} \Pi_{t}\left(r_{t}, e_{t}\right) g\left(t \mid r_{t}\right) d t \geq 0,
$$

where $\Pi_{t}\left(r_{t}, e_{t}\right)=\int_{b_{1}}^{b_{2}}\left(b-r_{t}(b)\right) f(b \mid t, e) d b \quad$ is expected gain with an agent of type $t$, and $g\left(t \mid r_{t}\right)$ is the posterior density of types (after updating by Bayes' rule). For the agent of type $t$, the choice of contract $r_{t}$ and of effort level $e$ should maximize $a\left(r_{\tau}\right) U_{t}\left(r_{\tau}, e\right)$, expected utility given the rule $a$ chosen by the principal.

The model as presented here is quite general, and not much can be said about equilibrium contracts. However, with few additional assumptions we can derive some properties which can be interpreted as no-cure-no-pay features of the equilibrium contracts. We assume in the following that the effect of competence and effort is compatible with (first order) stochastic dominance in the sense that for all $t, t^{\prime}$ and $e, e^{\prime}$, if $e^{\prime}>e$, then $F\left(\cdot \mid t, e^{\prime}\right)$ stochastically dominates $F(\cdot \mid t, e)$, and if $t^{\prime}>t$, then $F\left(\cdot \mid t^{\prime}, e\right)$ stochastically dominates $F(\cdot \mid t, e)$ (recall that for probability distributions $H, H^{\prime}$ on $\left[b_{1}, b_{2}\right], H^{\prime}$ stochastically dominates $H$ if $H^{\prime}(b) \leq H(b)$ for all $b$; intuitively, competence and effort will typically take higher values when drawn randomly in accordance with $F^{\prime}$ and $G^{\prime}$ than with $F$ and $G$ ).

Now we can state our first result, the proof of which may be found in the final section of the paper.

Proposition 1. In an equilibrium of the contracting game, the contract has the following properties:

(i) higher level of competence is awarded by higher expected remuneration,

(ii) if effort is irrelevant at low competence and reservation utility is strictly increasing in type, then the contract for the incompetent agent specifies a fixed payment $\rho_{0}$ independent of outcome, and competent types are paid more than $\rho_{0}$ only when a certain outcome threshold is exceeded.

The property in (ii) can be seen as generalized no-cureno-pay property; it establishes the existence of a threshold in outcome (thus defining what is meant by "cure") such that only outcomes above the threshold will give rise to payments above the minimum level.

In order to obtain more detailed knowledge of equilibrium contracts, we restrict attention to the simpler case where outcome, competence and effort can take only two values, so that $b$ is either $b_{1}$ or $b_{2}$, and $t, e \in\{0,1\}$, (agents can be competent, $t=1$, or incompetent, $t=0$, and they can choose high $(e=1)$ or low $(e=0)$ level of effort). The expected utility of the agent and expected net payoff of principal at the contract $r$ with $r\left(b_{1}\right)=r_{1}, r\left(b_{2}\right)=r_{2}$ are then

$U_{t}(r, e)=(1-p(t, e)) u\left(r_{1}, e\right)+p(t, e) u\left(r_{2}, e\right)$

for the agent with competence level $t$, and

$\Pi(r, e)=(1-q) \Pi_{0}(r, e)+q \Pi_{1}(r, e)$

with

$\Pi_{t}(r, e)=(1-p(t, e))\left(b_{1}-r_{1}\right)+p(t, e) u\left(b_{2}-r_{2}\right), t=0,1$

for the principal. Here we have used the notation $p(t, e)$ for the probability of high outcome $b_{2}$ given competence $t$ and effort $e$ and the notation $q$ for the prior probability of $t=1$. The assumption of stochastic dominance takes the form

$$
\begin{aligned}
& p(1,1) \geq p(1,0), p(0,1) \geq p(0,0) ; \\
& p(1,1) \geq p(0,1), p(1,0) \geq p(0,0) .
\end{aligned}
$$

At some point we also use an additional assumption to the effect that effort has little attraction if competence is low,

$$
V\left(b_{2}-b_{1}\right) \leq \frac{K(1)-K(0)}{p(0,1)-p(0,0)}
$$

to see what is implied by (3) consider a situation where an incompetent agent is offered all the gain $b_{2}-b_{1}$ when outcome is high but nothing when it is low; this may be considered as the maximal incentive that can be offered through a contract. Then expected utility is $p(0,1) V\left(b_{2}-b_{1}\right)$ if effort is high and $p(0,0) V\left(b_{2}-b_{1}\right)$ if low, and the expression in (3) states that the gain in expected utility obtained by choosing high rather than low effort cannot counterbalance the utility loss from putting up this additional effort.

When studying perfect Bayesian equilibria in the present context, it is possible and useful to distinguish between separating and pooling equilibria. In a separating equilibrium, the signal sent, in our case the contract $r$ proposed, by a competent agent differs from that chosen by an incompetent agent, and therefore, the principal can use the contract proposed to identify the type of the agent. By the equilibrium properties, it must not be advantageous for an agent of any type to switch to the contract proposal of the other type. The alternative to a separating equilibrium is a pooling equilibrium, where the contract is the same for both types, so that the principal cannot make any inference about agent type from observation of the equilibrium contract.

In the present simple setup, there are at most two equilibrium contracts, so in any equilibrium there are at most two 
equilibrium signals available. Therefore, we need an assumption pertaining to the way in which the principal interprets a signal which is not one of the two equilibrium contracts. Technically, we need the principal's subjective probability over types conditional on the (non-anticipated) signal observed. We shall assume that the principal adopts a sceptical attitude towards the agent in such situations: If a contract differs from those specified in the equilibrium strategies, then the principal will infer that the proposer is incompetent unless it violates individual rationality for the incompetent type.

Proposition 2. In the dichotomous model of contracting, and under our assumption on principal inference, we have that

(i) all equilibria are separating.

If, in addition, effort has low value for the incompetent agent as expressed in (3), then

(ii) the contract of the incompetent agent prescribes a fixed payment independent of outcome, and

(iii) the contract of the competent agent has the no-cureno-pay property in the sense that her payment at low outcome equals that of the incompetent agent.

The equilibrium contracts can be interpreted in terms of indifference curves, using the approach of Hirshleifer and Riley [21]. For this, we describe contracts not as pairs $\left(r\left(b_{1}\right), r\left(b_{2}\right)\right)$ as in the formalization above, but rather as pairs $(Z, R)$, where $Z=r\left(b_{2}\right)-r\left(b_{1}\right)$ and $R=r\left(b_{2}\right) ; Z$ is now a deduction in the payment caused by low outcome.

An indifference curve of an agent of type $t, t=0,1$, in the $(Z, R)$-space takes the form

$$
\left(1-p\left(t, e^{*}\right)\right) u\left(Z-R, e^{*}\right)+p\left(t, e^{*}\right) u\left(R, e^{*}\right)=U^{*}
$$

for some given level $U^{*}$ of (expected) utility. Here $e^{*}$ is the optimal effort level given $Z$ and $R$. This optimal level will be 0 in a region in the $(Z, R)$-plane containing all small values of $Z$ and 1 in the remaining part of the plane. The slope of the indifference curve is determined by the probability of low outcome, and it is greater for low than for high effort. Indifference curves have the convex shape shown due to the risk aversion of the agent, and they have a kink when they pass from the region of low effort to that of high effort.

For the principal facing an agent of known type $t$, isoprofit curves take the form

$$
\left(1-p\left(t, e^{*}\right)\right)\left(b_{1}-Z+R\right)+p\left(t, e^{*}\right)\left(b_{2}-R\right)=\text { constant, }
$$

where again $e^{*}$ is the agent's optimal choice of effort, depending on the contract. The indifference chart of the principal consists of two parts, both linear due to risk neutrality, and again the slope is determined by the probability of low outcome. The indifference curves have jumps at boundary between the low and high effort regions.

Using indifference curves of the principal and agent, a separating equilibrium can be represented as two points in the $(Z, R)$-plane. One of them corresponds to the contract proposed by the incompetent agent who will get no more than her reservation utility; in the extreme case where the incompetent agent has $p(0,0)=p(0,1)=1$, this indifference curve coincides with the $45^{\circ}$ line. The contract proposed by the competent agent in a separating equilibrium cannot be situated to the northwest of this line, since in that case the incompetent would be better off by showing off as competent. A point on the $45^{\circ}$ line and in the high effort region will be an equilibrium contract for the competent agent if it satisfies the individual rationality constraints of both principal and (competent) agent.

This equilibrium differs from what would have been obtained without hidden knowledge; indeed, the contract for the competent agent would then be inefficient in the sense that both principal and (competent) agent could achieve something better (contracts below the indifference curve of the principal and above that of the competent agent. The risk to be born by the agent is correspondingly higher, so in this sense the cost of asymmetric information concerning competence must be carried by the competent agent.

\section{DOES THE MODEL EXPLAIN REAL WORLD CONTRACTS?}

To what degree does our model apply to the contractual forms which were mentioned in the introduction (maritime salvage, contingent fees and unconditional service guarantees)? In the following, we will look first at maritime salvage and US tort contingent fee contracting in these regards. We then follow with a brief examination of the rise of unconditional guarantee contracting.

Maritime salvage and contingent fees. Despite historical differences as to the origins and history of no-cure-no-pay and no-win-no-fee principles, there is considerable evidence supporting our results. Critical to both contractual provisions is the principal's ignorance of the capabilities of various potential agents, and the degree of risk in salvage as well as pursuit of a tort law suit.

As mentioned earlier, Rhodian law three thousand years ago specified not only no-cure-no-pay, but also the terms of the reward ( 20 percent of the salved value) and the lien. Roman law also codified some of the principles of salvage contracting, particularly in the Justinian Digest. Six hundred years later the Trani Consuls' Ordinances of the Customs of the Sea provided further codification. The result has been that these codifications and others have led to what is currently considered jus gentium, the Law of Nations [22]. For most of this period, it has been impossible for a ship owner or master to know of his potential salvors' reputation before concluding the contract. As the risk of salvage in the early days of sail was considerable (a clumsily performed towing job could easily dismast the salvor's vessel), the number of agents willing and able to provide salvage was limited much as in our theoretical discussion.

Also in American tort law, there was an early need for signalling capability in a frontier society where the practice of law alone was not necessarily a guarantee of the quality of the juridical assistance that one obtained. The use of a "lien" on the damages recovered on successful suits had the further advantage of making tort law suits affordable in circum- 
stances where plaintiffs were often poor or lacked money. The importance of these beliefs was enhanced by the legal ethics of the profession which forbade lawyer advertisement. It was not until 1977 that the Supreme Court struck down this prohibition.

In both maritime salvage and US tort law, one could argue that lack of knowledge about agent capability has become less important over time. Firstly, other reputation mechanisms have filled the historic void. Thus, a shipmaster or owner today is well acquainted with the half dozen or so of the most prominent salvage firms, and no-cure-no-pay signalling is superfluous. Similar tendencies exist within the US legal profession, although professional codes often inhibit competition in terms of the fee share of successful settlements (to take US medical malpractice, for instance, an exhaustive study of contractual provisions [23] has discovered that only one percent of contracts provided for payment according to an hourly fee rather than on a contingent basis. Of the other contracts, 80 percent were on a fixed contingency basis, some 30 percent of which specified a fee of 33.3 percent, and 46.3 percent, a fee of 40 percent).

Secondly, governmental regulation has done much to deprive ship-owner and tort plaintiff alike of contractual choice. Thus coastal states can insist that vessels in distress must sign a particular salvage contract, generally (but not necessarily) the Lloyds Open Form contract, and employ professional salvors, in particular salvage firms based in the coastal state concerned. Numerous statutes impose limitations on contingent fees. Thus attorney's fees under the Federal Tort Claims Act are limited by the Judicial Code to no more than 25 percent after the suit is filed, and no more than 20 percent for out of court settlements. Additionally the various states have their own regulations [1].

The combination of professional restraints on trade and governmental regulation affect the assumptions of our model, as they together specify contractual terms of payment and restrict contractual choice. This means that the pure case for a no-cure-no-pay contract may have existed in the past, but it is more dubious if it does so today.

Unconditional service guarantees: No-satisfaction-nopay. The degree to which unconditional service guarantees are thought to be of the same contractual species as the other two is understandable. The institutional context in which unconditional guarantees are incorporated into commercial contracts is supportive of our model with its emphasis on the role of beliefs. This is particularly the case of unconditional guarantees as offered by professional service firms. Here the prices for services are high as they are in salvage and US tort law. Services are highly customised, and buyer resistance is high. There are two conditions behind the use of unconditional guarantees:

Firstly, brand distinction is hard to achieve. This is in part due to the nature of the services being provided, but also to professional ethical restrictions which obtain for such firms.

Secondly, recourse to unconditional guarantees is a function of a firm's desire to expand its market share, to win new customers from other firms [5]. An inability to establish brand distinction or other differentiating characteristics is sufficient to qualify for a variation of our hidden information assumption. Unlike the case of ship owner or tort plaintiff who in our model is confronted with a "first time in a lifetime" situation in which principal selection of an agent is necessarily confined to a comparison of contracts on offer, principals confronting the selection of a management consultant can have many alternative sources of information as to consultant competence, but that these sources of information are so unreliable that the principal feels compelled to confine his search to the contracts offered him.

Does this mean that unconditional guarantees in ex ante contracting incentive terms are identical to no-cure-no-pay or no-win-no-fee provisions? Not necessarily; in fact they may differ in manners more subtle than those indicated by our model.

Firstly, since unconditional guarantees are often an additional agent signal to those already existing, the claim of nosatisfaction-no-pay can have the reverse impact to that desired. If a US plaintiff engages a lawyer to pursue a tort suit on his behalf, she now can rely on advertising information (since 1977). She can also utilise "word of mouth." That she will pay her lawyer on a contingent basis will not concern her in that she knows that this is industry practice. Contrast this situation with one in which firms already have well established reputations and there is no tradition of nosatisfaction-no-pay. In this latter situation, the addition of a unconditional guarantee can signal quite the opposite of what is intended, that potential principals (customers) may wonder why such a guarantee "needs stating in the first place" [4]. Furthermore the guarantee may annoy customers as these may have assumed that they already had such an agreement with the agent, albeit an implicit agreement. Such considerations will limit the use of unconditional guarantees and confine it to service activities where the principal cannot differentiate among potential agents and is forced to rely on contract type to reveal agent competence.

Secondly, where the nature of the lien in both the salvage and contingency fee contracts is well-defined and the settlement procedure is supported by legal institutions, the "lien" and settlement procedure in unconditional guarantees are not. Whereas agent failure in salvage and American tort cases results in an unequivocal loss of agent payment, the situation is different in case of unconditional guarantees. Take, for example, corporate headhunting and recruitment consultancy contracts, a subject of study by Batstone and Clark [5] whose results are in part summarised in Table 1.

As can be seen in the table, guarantees are not universally used in this branch, possibly a sign of their separating equilibrium properties. More important for our purposes is that in none of these contractual relationships is agent failure penalised in the same manner as in the case of maritime salvage and contingent fee contracts. Losses are incurred, but are minimised. The guarantees tend to tie the client to the consulting firm even in the case of failure. Where reimbursement is considered, it is only partial reimbursement. 
Table 1. Frequency of Service Guarantees in Corporate Head Hunting/Recruitment Consultancy Contracts

\begin{tabular}{|l|c|c|}
\hline \multicolumn{1}{|c|}{ Service Guarantee (By Type) } & Head Hunter Consultancy & Recruitment Consultancy \\
\cline { 2 - 4 } & \multicolumn{2}{|c|}{ pet. } \\
\hline \hline Guarantee to restart process should recruit leave client during a specified period & 75.1 & 65.8 \\
\hline Partial reimbursement if recruit leaves the firm during a specified period & 33.3 & 51.8 \\
\hline Continue recruitment process if recruit/candidate rejects client's offer & 89.1 & $\ldots$ \\
\hline $\begin{array}{l}\text { Continue recruitment process if client does not recruit any of the candidates offered by } \\
\text { consultancy/agent }\end{array}$ & 88.1 & $\ldots$ \\
\hline
\end{tabular}

Source: Batstone and Clark [5].

\section{CONCLUDING REMARKS}

What might be defined as a generic form of no-cure-nopay contracts, contracts involving not only marine salvage, but also US tort legal services, and a host of unconditional guarantee contractual forms, has been the focus of our attention in this paper. These contractual forms are not the only ones in which agents are not compensated in the event of failure, but receive payment upon success. Indeed, such contracting practices are far more widespread than is generally thought. For example, estate agent contracts are also often structured on a no-sale-no-fee basis. We have not sought to be all-inclusive in our analysis. Rather our objective has been to model the general conditions under which both agent and principal will strictly prefer this generic form of contracting to any other alternative. We have modelled these conditions.

Applying our model to marine salvage, US legal tort, and those professional services underwritten by unconditional guarantees demonstrates the difficulties of applying our model's use of strict preferences in two manners: Firstly, there are professional services in which the nature of competitive signalling has changed significantly over time, but where contracting practices remain unaltered. Here one can mention the use of no-cure-no-pay in maritime salvage, and, perhaps, no-win-no-fee in US tort cases. Secondly, there are services which may not have originally used such contract signalling, but which are adopting it as a supplement to other reputation mechanisms. The increasing use of professional service guarantees by, for example, management consulting firms, is a case in point here. These variants, however, do not attenuate the explanatory force of our approach; rather they tend to indicate that the underlying variables in our model have led to such contracting in various industries, and that such contracting contains significant elements of hidden information to be disclosed in separating equilibria despite significantly different historical and institutional contexts.

\section{PROOFS OF PROPOSITIONS}

In this section we give formal statements of the propositions in Section 2 as well as their proofs. Using the notation from Section 2, we may write expected utility of the agent of type $t$ as

$U_{t}(r, e)=\int_{b_{1}}^{b_{2}} V(r(b)) f(b \mid t, e) d b-K(e)$

and overall expected net payoff as
$\Pi(r, e)=\int_{0}^{1} \Pi_{t}(r, e) g(t) d t=\int_{0}^{b} \int_{b_{1}}^{b_{2}}(b-r(b)) f(b \mid t, e) g(t) d b d t$.

The equilibrium conditions for the strategy pair $\left(a,\left(r_{t}, e_{t}\right)_{t \in[0,1]}\right)$ are as follows: For the principal,

$a\left(r_{t}\right)=1$ if and only if $\int_{b_{1}}^{b_{2}} \Pi_{t}\left(r_{t}, e_{t}\right) g\left(t \mid r_{t}\right) d t \geq 0$,

where $g\left(t \mid r_{t}\right)$ is the posterior density of types after updating by Bayes' rule; for the agent of typet, the choice of contract and of effort level solves the problem

$\max _{\left\{(r, e) \mid U_{t}(r, e) \geq U_{t}^{0}\right\}} a(r) U_{t}(r, e)$.

If the agent's choice of effort given the contract $r$ is unique, we may suppress it in the notation, writing $f^{*}(b \mid t)$ for the conditional density of $b$ given the type $t$ and the optimal level of effort connected with the equilibrium contract $r_{t}$.

Proposition 1 can now be restated as follows:

Proposition 1. Let $\left(a,\left(r_{t}, e_{t}\right)_{t \in[0,1]}\right)$ be an equilibrium, and assume that optimal agent effort is uniquely determined. Then the following hold:

$$
\begin{aligned}
& \text { for } \quad \mathrm{t}^{\prime} \quad>\quad \mathrm{t}, \quad \text { if } \quad r_{t^{\prime}} \neq r_{t}, \quad \text { then } \\
& \int_{b_{1}}^{b_{2}} r_{t^{\prime}}(b) f^{*}\left(b \mid t^{\prime}\right) d b>\int_{b_{1}}^{b_{2}} r_{t}(b) f^{*}(b \mid t) d b .
\end{aligned}
$$

(ii) if $F(\cdot \mid 0, e)$ does not depend on e, and $U_{t^{\prime}}^{0}>U_{t}^{0}$ for $\mathrm{t}^{\prime}>\mathrm{t}$, then $r_{0}$ is constant and there is $\bar{t}>0$ and $b_{\bar{t}}>b_{1}$ such that $r_{\bar{t}}(b) \leq r_{0}(b)$ for $b \leq b_{\bar{t}}$.

\section{Proof}

(i) We have $\int_{b_{1}}^{b_{2}} V\left(r_{t}(b)\right) f(b \mid t, \hat{e}) d b>\int_{b_{1}}^{b_{2}} V\left(r_{t}(b)\right) f^{*}(b \mid t) d b$ by stochastic dominance (since $V\left(r_{t}(\cdot)\right.$ ) is nondecreasing), where $\hat{e}$ is such that $f(b \mid t, \hat{e})=f^{*}(b \mid t)$. Thus, there is an effort level $\hat{e}$ and a contract $r_{t}$ for which

$U_{t^{\prime}}\left(r_{t}, \hat{e}\right)>\int_{b_{1}}^{b_{2}} r_{t}(b) f^{*}(b \mid t) d b$.

By the equilibrium property, we have that 
$\int_{b_{1}}^{b_{2}} r_{t^{\prime}}(b) f^{*}\left(b \mid t^{\prime}\right) d b \geq \int_{b_{1}}^{b_{2}} r_{t}(b) f\left(b \mid t^{\prime}, \hat{e}\right) d b>\int_{b_{1}}^{b_{2}} r_{t}(b) f^{*}(b \mid t) d b$,

which gives the desired conclusion.

(ii) Since $F(\cdot \mid 0, e)$ is independent of $e$, so is $f(\cdot \mid 0, e)$, so $f^{*}(b \mid 0)=f(b \mid 0,0)$. Then $r_{0}$ must be constant, $r_{0}(b)=\rho_{0}$ for all $b$, since otherwise by strict concavity of $V, U_{0}(r, 0)$ could be increased with $\Pi(r, e)$ unchanged by replacing $r_{0}$ by its expected value $\int_{b_{1}}^{b_{2}} r_{0}(b) f^{*}(b \mid 0) d b$, contradicting the equilibrium properties of $r$. Assume that $t>$ 0 and that $r_{t}$ is accepted by the principal. If $r_{t}(b) \geq \rho_{0}$ for all $b$ and $r_{t} \neq r_{0}$, then

$$
\int_{b_{1}}^{b_{2}} V\left(r_{t}(b)\right) f^{*}(b \mid 0) d b>V\left(\rho_{0}\right),
$$

so that the contract violates the optimality condition defining an equilibrium. We conclude that $r_{t}(b)<\rho_{0}$ for some $b<b_{t}$, where $b_{t}>b_{1}$. Since the optimal contract is nondecreasing for each $t$, we have that property (ii) must be satisfied.

In the proof of Proposition 2, we need a lemma. Let $e_{t}^{*}(r)=\operatorname{argmax}_{e} U_{t}(r, e)$ be the optimal effort level of the agent of type $t$ at the contract $r$.

Lemma 1. Let $\left(r_{0}, r_{1}\right)$ be the contracts proposed by agents of types 0 and 1 in an equilibrium. Then

$r_{1}$ maximizes $U_{1}\left(r, e_{1}^{*}(r)\right)$ under the constraints

$U_{0}\left(r, e_{0}^{*}(r)\right) \leq U_{0}\left(r_{0}, e_{0}^{*}\left(r_{0}\right)\right), \quad \Pi_{1}\left(r, e_{1}^{*}(r)\right) \geq 0$, $U_{1}\left(r, e_{1}^{*}(r)\right) \geq U_{1}^{0}$,

either $r_{0}$ is accepted, and $r_{0}$ maximizes $U_{0}\left(r, e_{1}^{*}(r)\right)$ under the constraints

$$
\Pi_{0}\left(r, e_{0}^{*}(r)\right) \geq 0, U_{0}\left(r_{0}, e_{0}^{*}(r)\right) \geq U_{0}^{0},
$$

or $r_{0}$ is rejected, and the set of contracts $r$ satisfying (5) is empty.

Proof: (i) If $\left(r_{0}, r_{1}\right)$ is a separating equilibrium, then incentive compatibility for type $t=0$ gives

$U_{0}\left(r_{1}, e_{0}^{*}\left(r_{1}\right)\right) \leq U_{0}\left(r_{0}, e_{0}^{*}\left(r_{0}\right)\right), \quad \Pi_{1}\left(r, e_{1}^{*}(r)\right) \geq 0 \quad$ holds since the principal accepts $r_{1}$, and finally $U_{1}\left(r_{1}, e_{1}^{*}(r)\right) \geq U_{1}^{0}$ is the participation constraint of $t=1$. Moreover, if there is a contract $r^{\prime}$ satisfying the constraints in (4) but with $U_{1}\left(r^{\prime}, e_{1}^{*}\left(r^{\prime}\right)\right)>U_{1}\left(r_{1}, e_{1}^{*}\left(r_{1}\right)\right)$, then $r_{1}$ is not an optimal strategy for type 1 . The condition (ii) of the proposition is a direct consequence of the definitions.

The formal version of Proposition 2 is as follows.

Proposition 2. Assume that $B=\left\{b_{1}, b_{2}\right\}, T=\{0,1\}$, $E=\{0,1\}$, and that the principal uses the sceptical method of inference given out-of-equilibrium signals. Let $r$ be an equilibrium contract, where the principal accepts at one or both components. Then

(i) $\quad r=\left\{r_{0}, r_{1}\right\}$ is separating.

If effort has low value for the incompetent agent as given by (3), then

$$
r_{0}\left(b_{1}\right)=r_{0}\left(b_{2}\right)=\rho_{0},
$$

(iii) $r_{1}\left(b_{1}\right) \leq r_{0}\left(b_{1}\right)$.

\section{Proof}

(i) We show that under the assumptions stated, there are no pooling equilibria. Suppose to the contrary that $(\hat{r}, \hat{r})$ with $\hat{r}=\left(\hat{r}\left(b_{1}\right), \hat{r}\left(b_{2}\right)\right)$ is a pooling equilibrium.

We claim first that $\Pi_{0}\left(\hat{r}, e_{0}^{*}(\hat{r})\right) \leq 0$. Indeed, if $\Pi_{0}\left(\hat{r}, e_{0}^{*}(\hat{r})\right)>0$, then a contract $r^{\prime \prime}$ with $r^{\prime \prime}\left(b_{1}\right)-\hat{r}\left(b_{1}\right)>\varepsilon, \quad r^{\prime \prime}\left(b_{2}\right)-\hat{r}\left(b_{2}\right)>\varepsilon$, for $\varepsilon>0$ small enough would satisfy $\Pi_{0}\left(r^{\prime \prime}, e_{0}^{*}\left(r^{\prime \prime}\right)\right)>0 \quad$ and $U_{0}\left(r^{\prime \prime}, e_{0}^{*}\left(r^{\prime \prime}\right)\right)>U_{0}\left(\hat{r}, e_{0}^{*}(\hat{r})\right)$, contradicting (ii) of Lemma 1 , thus proving our claim.

Next, using that due to (2) we have $\Pi_{1}\left(\hat{r}, e_{1}^{*}(\hat{r})\right)>\Pi_{0}\left(\hat{r}, e_{0}^{*}(\hat{r})\right)$, we get from the participation constraint $q \Pi_{1}\left(\hat{r}, e_{1}^{*}(\hat{r})\right)+(1-q) \Pi_{0}\left(\hat{r}, e_{0}^{*}(\hat{r})\right) \geq 0 \quad$ that $\Pi_{1}\left(\hat{r}, e_{1}^{*}(\hat{r})\right)>0$, so that there is a neighborhood $U$ of $r$ such that for separating contracts $\left(\hat{r}, r_{1}^{\prime}\right)$ with $r_{1}^{\prime} \in U$, the principal will accept $r_{1}^{\prime}$ as long as $e^{*}\left(r^{\prime}\right)=e^{*}(\hat{r})$.

Now there are two cases to consider: (a) $U_{1}(\hat{r}, 0)>U_{1}(\hat{r}, 1)$ : Here $e_{1}^{*}(\hat{r})=0$, and $e^{*}\left(r^{\prime}\right)=0$ for the contract $r^{\prime}$ with $r^{\prime}\left(b_{1}\right)=\hat{r}\left(b_{1}\right)+\varepsilon, \quad r^{\prime}\left(b_{2}\right)=\hat{r}\left(b_{2}\right)$, if $\varepsilon>0$ is chosen small enough. We have that $r^{\prime}$ satisfies the constraints in (3) and that $U_{1}\left(r^{\prime}, e_{1}^{*}\left(r^{\prime}\right)\right)>U_{1}\left(\hat{r}, e_{1}^{*}(\hat{r})\right)$. By Lemma $1, \quad r^{\prime}$ is an improvement for type 1. (b) $U_{1}(\hat{r}, 0) \leq U_{1}(\hat{r}, 1)$. Now $e_{1}^{*}(\hat{r})=1$ and a contract $r^{\prime}$ with $r^{\prime}\left(b_{1}\right)=\hat{r}\left(b_{1}\right), r^{\prime}\left(b_{2}\right)=\hat{r}\left(b_{2}\right)+\varepsilon$ is an improvement for type 1 for $\varepsilon>0$ small enough.

(ii) Assume that $r_{0}$ is constant, so that optimal effort is $e_{0}^{*}\left(r_{0}\right)=0$, and suppose that the contract is changed by adding $h>0$ in the case that outcome is $b_{2}$. If effort changes to 1 , then expected utility changes by

$\Delta U_{0}=[p(0,1)-p(0,0)]\left[V\left(\rho_{0}+h\right)-V\left(\rho_{0}\right)\right]-[K(0)-K(1)]$.

By concavity, $V\left(\rho_{0}+h\right)-V\left(\rho_{0}\right) \leq V^{\prime}\left(\rho_{0}\right) h$, and since $h \leq b_{2}-b_{1}$, we get that

$$
\Delta U_{0}=[p(0,1)-p(0,0)] V^{\prime}\left(\rho_{0}\right) h-[K(0)-K(1)]
$$

showing that optimal effort level remains 0 . Since effort level is always 0 , overall utility of type 0 will be maximized using a constant contract. 
(iii) Assume that $r_{1}\left(b_{1}\right)>r_{0}\left(b_{1}\right)$. If $r_{1}\left(b_{2}\right) \geq r_{0}\left(b_{2}\right)$, then contract $r_{1}$ is better for type 0 that $r_{0}$, contradicting equilibrium. Therefore $r_{1}\left(b_{2}\right)<r_{0}\left(b_{2}\right)$. Letting $\rho_{1}$ and $\rho_{2}$ denote payment at outcome $b_{1}$ and $b_{2}$ respectively, we get from (1) that a change $\left(d \rho_{1}, d \rho_{2}\right)$ in the contract for type 1 with $d \rho_{2}>0$ leaves this agent indifferent if $-\frac{d \rho_{2}}{d \rho_{1}} \geq \frac{1-p\left(1, e_{1}^{*}\left(r_{1}\right)\right)}{p\left(1, e_{1}^{*}\left(r_{1}\right)\right)} \frac{V^{\prime}\left(r_{1}\left(b_{1}\right)\right.}{V^{\prime}\left(r_{1}\left(b_{2}\right)\right)}$; here the first factor on the right-hand side is the slope of the isoprofit curve of the principal, and if $r_{1}\left(b_{2}\right)<r_{1}\left(b_{1}\right)$, then second factor is $<1$ by strict concavity of $V$, so that the contract $r_{1}$ could be improved with the principal's acceptance. We conclude that $r_{1}\left(b_{2}\right) \geq r_{1}\left(b_{1}\right)$, which in view of (ii) gives us a contradiction, showing that $r_{1}\left(b_{1}\right)<r_{0}\left(b_{1}\right)$.

\section{REFERENCES}

[1] Fisher JM. Contingent and noncontingent Attorney's fees in personal injury cases. Contemporary Policy $1988 ; 6: 108-22$.

[2] Landes WM, Posner RA. Altruism in law and economics. Am Econ Rev Pap Proc 1978; 58: 417-21.

[3] Landes WM, Posner RA. Salvors, Finders, Good Samaritans, and other Rescuers: An economic study of laws and altruism. J Legal Stud 1978; 7: 83.

[4] Hart CWL, Schlesinger LA, Maher D. Guarantees come to professional service firms. Sloan Manage Rev 1992; 33: 19-29.

[5] Batstone S, Clark T. Trust and the headhunter. Multinational Business Spring 1990: 1-9.

[6] Rubinfeld DL, Scotchmer S. Contingent fees for Attorneys: An economic analysis. RAND J Econ 1993; 24: 343-56.
[7] Emons W. Expertise, Contingent fees and insufficient attorney effort. Int Rev Law Econ 2000; 20: 21-33.

[8] Gravelle H, Waterson M. No win, no fee: Some economics of contingent legal fees. Econ J 1993; 103: 1205-21.

[9] Schwartz ML, Mitchell DJB. An economic analysis of the contingent fee in personal injury legislation. Stanford Law Rev 1970; 22: 1125-62. 1125-62.

[10] Hay BL. Optimal contingent fees in a world of settlement. J Legal Stud 1997; 26: 259-78.

[11] Rickman N. Contingent fees and litigation settlement. Int Rev Law Econ 1999; 19: 295-317.

[12] Hay BL. Contingent fees and agency costs. J Legal Stud 1996; 25 : 503-33.

[13] Shavell S. Suit settlement and trial: A theoretical analysis under alternative methods for the allocation of legal costs. J Legal Stud 1982; 2: 55-81.

[14] Santore R, Viard AD. Legal fee restrictions, moral hazard and attorney rights. J Law Econ 2001; 44: 549-72.

[15] Rosen S. The market for lawyers. J Law Econ 1992; 35: 215-47.

[16] Laffont JJ, Matrimont D. The theory of incentives: The principalagent model. Princeton: Princeton University Press 2002.

[17] Schoonbeek L, Kooreman P. No cure, be paid: super-contingent fee contracts. Appl Econ Letters 2005; 12: 49-51.

[18] Ross S. The economic theory of agency: The principal's problem. Am Econ Rev 1973; 63: 134-39.

[19] Mirrlees JA. The optimal structure of incentives and authority within an organization. Bell J Econ Manage Sci 1976; 7: 105-31.

[20] Grossman S, Hart O. An analysis of the principal-agent problem. Econometrica 1983; 52: 1-45.

[21] Hirshleifer J, Riley JG. The analytics of uncertainty and information. Cambridge England: Cambridge University Press 1992.

[22] Kerr DA. The past and future of no cure-no pay. J Mar Law Com 1992; 23: 410-27.

[23] Sloan FA, Githens PB, Clayton EW, Hickson GB, Gentile DA, Parlett DF. Suing for medical malpractice. Chicago, University of Chicago Press 1993. 